\title{
A ESCOLA NORMAL REGIONAL NO INTERIOR DO PARANÁ: A REALIDADE E A IDEALIDADE DE SUAS PRÁTICAS PEDAGÓGICAS
}

\author{
Luciana Hervatini ${ }^{1}$ \\ Secretaria de Estado da Educação do Paraná (SEED/PR) \\ Analete Regina Schelbauer ${ }^{2}$ \\ Universidade Estadual de Maringá (UEM)
}

\section{RESUMO}

O presente artigo derivou-se de uma pesquisa Stricto-Sensu realizada pela UEM, tendo como questão norteadora de nossa investigação quais seriam as práticas consideradas pedagógicas presentes na formação de professores pelas Escolas Normais Regionais do norte do Paraná. A escolha do objeto de estudo e da delimitação espaço-temporal se deu pela necessidade de uma investigação mais específica sobre a formação dada pelos Cursos Normais Regionais do interior do Estado. Buscou-se recuperar e analisar as práticas pedagógicas das Escolas Normais Regionais de Apucarana e de Maringá sob a influência da Pedagogia da Escola Nova e das orientações oficiais. Utilizamos como metodologia a pesquisa bibliográfica e documental de cunho qualitativo e orientamo-nos nas produções científicas relacionadas ao nosso objeto de estudo e em fontes históricas das escolas pesquisadas. De peso para a discussão das práticas pedagógicas das Escolas Normais Regionais do interior foram os trabalhos de Erasmo Pilotto (1910-1992), como diretor da Escola de Professores de Curitiba e como Secretário de Educação do Paraná (1948-1950). Como resultado identificamos quais foram as práticas pedagógicas das escolas pesquisadas e em que medida o período urbano-industrial e o escolanovismo no Paraná, sob as orientações de Pilotto determinaram a formação de professores no interior do Paraná. Palavras-chave: Práticas Pedagógicas; Escola Normal Regional; Erasmo Pilotto.

\section{REGIONAL TRAINING COLLEGE IN THE INTERIOR OF THE STATE OF PARANÁ, BRAZIL: REALITY AND IDEAL OF THEIR PEDAGOGICAL PRACTICES}

\begin{abstract}
Current essay is a consequence of a stricto sensu research undertaken at the UEM. Its guiding issue consists of the pedagogical practices in teachers' formation at the Regional Training Colleges in the northern region of the state of Paraná, Brazil. The choice of the study object and the space-time limitation are due to the need of a more specific investigation on the formation given by Regional Training Colleges in the interior of the state of Paraná. The pedagogical practices of the Regional Training Colleges of Apucarana and Maringá are analyzed with a focus on the influence of the New School Pedagogy and official guidelines. Methodology comprised a bibliographical and documental qualitative and the scientific production related to the study object and the historical sources of the schools under analysis were the guidelines. Discussions on the pedagogical practices of the Regional Training Colleges were highly affected by research by Erasmo Pilotto (19101992) when he was headmaster of the Teachers' Formation College of Curitiba and Secretary of Education of the state of Paraná (1948-1950). Results showed the pedagogical practices at the Regional Training Colleges and revealed the importance of Pilotto's guidelines for teachers' formation in the interior of the state of Paraná within the context of the state's industrialization and urbanization period and the New School Movement. Keywords: Pedagogical practices; Regional Training Colleges; Erasmo Pilotto.
\end{abstract}


Tendo como objeto de estudo as práticas pedagógicas desenvolvidas nas Escolas Normais Regionais ${ }^{3}$ Pestalozzi, de Apucarana, e Eduardo Claparèd, de Maringá, criadas no norte novíssimo ${ }^{4}$ o Paraná, procuramos explanar como as ações realizadas pelos regionalistas destas escolas se consubstanciaram no contexto nacional-desenvolvimentista e sob a influência do movimento da Escola Nova no Paraná.

Como responsável pelos programas de ensino para os Cursos Normais no Paraná, Erasmo Pilotto elaborou e acompanhou as políticas educacionais para estes cursos. Desta forma, foram consideradas, as publicações Prática da Escola Serena (1946) e A Educação é Direito de Todos (1952), no intuito de caracterizar dois momentos distintos em que as práticas pedagógicas dos normalistas foram pensadas por Erasmo Pilotto para as Escolas Normais Regionais do Paraná.

Para explanarmos estas ações das Escolas Normais Regionais de Apucarana e Maringá, classificamo-las didaticamente para possibilitar a compreensão de como estas atividades se consubstanciaram em práticas pedagógicas presentes no processo educativo de formação de professores.

\section{Práticas pedagógicas de manutenção e de organização das instituições de ensino primário}

De acordo com o Programa para as Escolas Normais do Paraná nos últimos anos da década de 1940, os regionalistas formados para a zona rural atenderiam à demanda do ensino primário paranaense, especialmente nas regiões em crescimento, como o norte do Estado, com a finalidade de melhorar o nível de escolarização da população e propor soluções para os problemas locais com conhecimentos que os equiparassem às condições de vida urbana. Ou seja, que a educação primária rural não se diferenciasse da urbana no sentido de abranger "verdadeira cultura, de sentido humano." (PILOTTO, 1946, p. 47). Desta forma, a postura de líder comunitário, preocupado com a melhoria da qualidade de vida dos alunos e de suas famílias, seria desenvolvida pelos regionalistas.

Os currículos das Escolas Normais Regionais pesquisadas apresentaram esta orientação, estando em conformidade com a Lei Orgânica do Ensino Normal, sob forma de disciplinas que contemplavam as atividades manuais e econômicas da região.

Nos registros históricos das escolas pesquisadas identificamos as práticas desenvolvidas pelos regionalistas em escolas isoladas que se caracterizavam especificamente pelas atividades de manutenção das instalações físicas destas escolas. Como nos mostra o registro de uma destas atividades:

No dia 14 de setembro [de 1959] houve uma festa para comemorar a reforma e melhoramento da escola isolada "Fernando Costa", feita pelos alunos da $4^{\text {a }}$ série desta Escola [Normal]. Na ocasião, estiveram presentes os pais dos alunos, bem como o representante do Sr. Prefeito, que disse belas palavras de elogios às normalistas. $\mathrm{O}$ trabalho dos nossos alunos foi bastante difícil em virtude da distância até a escola isolada, mas, mesmo assim, conseguiram ótimos resultados. Trocaram as telhas que estavam quebradas, arrumaram as portas e janelas, colocaram os caixilhos e vidros, encortinaram, pintaram as paredes, lixaram e envernizaram as carteiras e, além disso, prepararam grande parte de 
material didático para ser usado pela professôra da referida escola. Em seguida, algumas alunas, a professôra de Didática e o representante do Sr. Prefeito foram fazer um levantamento da escola isolada "Erasto Gaertner", onde pretendem trabalhar ainda êste ano. (COLÉGIO ESTADUAL ALBERTO SANTOS DUMONT, 2010, Livro Ata n. 1, p. 8v.).

A expectativa do governo federal e estadual era preparar professores regentes de ensino primários para a zona rural a fim de transmitir-lhes conhecimentos para melhor viverem nas localidades em que moravam, particularmente nas escolas rurais recéminauguradas. (MIGUEL, 1997). No entanto, nas cidades pesquisadas de Apucarana e Maringá, não se desmereceu o fato de que as Escolas Normais Regionais oportunizaram a realização de atividades aos regionalistas nos grupos escolares urbanos, já que, nestas cidades, havia um grupo escolar anexo à Escola Normal Regional e outro anexo à Escola Normal Secundária.

Pelos relatos em documentos históricos, destacamos que, tanto no grupo escolar quanto nas escolas isoladas, os alunos da Escola Normal Regional eram responsáveis pela manutenção física e confecção de material pedagógico, já que eram orientadas pelos próprios professores e realizadas como parte do conteúdo de suas disciplinas. Nas atividades práticas das demais disciplinas, também eram confeccionados materiais didáticos para serem doados às escolas isoladas e aos grupos escolares.

Ao identificarmos estas atividades, entendemos que foram realizadas pelos regionalistas em cumprimento ao Artigo 47 da Lei Orgânica do Ensino Normal, que normatizava: "Todos os estabelecimentos de ensino normal manterão escolas primárias anexas para demonstração e prática de ensino" e, em seu parágrafo primeiro, especificava que "cada curso normal regional deverá manter, pelo menos, duas escolas primárias isoladas." (BRASIL, 1946b).

O termo 'manter' possibilita inferir que as atividades de conserto das escolas rurais e doação de material didático para os grupos escolares na cidade representavam a interpretação dada ao artigo da lei. Nesse sentido, o governo do Estado se desobrigava a manter estas escolas primárias, minimizando recursos destinados para este fim, além de sobrepor-se à manutenção pedagógica nas escolas isoladas e nos grupos escolares, ou seja, o acompanhamento e assessoria das atividades, métodos e técnicas de ensino.

Concordamos com Miguel (1997a), de que a expectativa do governo federal e estadual em relação aos regionalistas era preparar professores regentes para o ensino primário para atuar na zona rural a fim de que estes transmitissem, nas escolas rurais recém-inauguradas, conhecimentos para melhorar a qualidade de vida das populações daquelas localidades. Mas no caso das cidades de Apucarana e Maringá, as práticas pedagógicas das normalistas regionalistas foram desenvolvidas tanto no meio rural, quanto urbano, já que nestas cidades havia a modalidade de grupo escolar anexo a Escola Normal Regional. Seguramente, o maior grau de abrangência das práticas pedagógicas ocorreu no âmbito das escolas isoladas da zona rural, que figuravam como campo de observação da realidade dos alunos e de atuação das normalistas para manutenção física das condições da escola. 


\section{Práticas pedagógicas de caráter filantrópico e assistencialista}

Podemos entender que o movimento de urbanização das cidades do interior e as situações de precariedade de uma camada da população, durante as décadas de 1940 até a década de 1960, não tenham se diferenciado substancialmente das demais regiões interioranas do Paraná. Conforme argumenta Miguel (1997, p. 24):

À medida que os núcleos [populacionais] se urbanizavam, o processo de urbanização criava na população a necessidade de outras formas de participação social que não aquelas do meio rural e a população reconhecia, na escola, uma das mediações para se inserir, de modo satisfatório, nas novas relações de produção.

Em meio a esta realidade, as Escolas Normais de Apucarana e Maringá não ficaram alheias e participaram de ações que visavam à melhoria das condições da população carente. Algumas destas práticas recorrentes eram incentivadas e realizadas durante a formação dos regionalistas, sendo consideradas como atividades de filantropia ou de caráter assistencialistas.

Estas atividades se configuravam em visitas a asilos, creches e penitenciárias, locais onde levavam mantimentos, roupas e material de higiene. Também participavam de desfiles de moda em eventos sociais para angariar fundos para doações de cestas básicas e de campanhas de arrecadação e doação de agasalhos, mamadeiras, leite e alimentos, além de auxiliarem em campanhas de vacinação infantil. (APUCARANA, 1994, 2011; INSTITUTO DE EDUCAÇÃO ESTADUAL DE MARINGÁ, 2006).

Muitas dessas atividades ocorriam durante o período de aulas dos regionalistas e ficavam diretamente sob a orientação de seus professores. Constatamos este fato em registros dessas práticas como estas realizadas por alunos da Escola Normal Regional Pestalozzi, de Apucarana, em 1960:

Durante a Semana da Criança a Escola Normal Regional apresentou uma homenagem a oito bebês, filhos de mães pobres, ofertando-lhes enxovais completos, confeccionados pelas alunas desta escola, sob a orientação da professora de Trabalhos Manuais, Da. Célia Martins Gallucci. Antes desta oferta, os referidos enxovais permaneceram expostos numa das vitrinas da Casa Rosa S. A., onde foram admirados pela população apucaranense [...]. (COLÉGIO ESTADUAL ALBERTO SANTOS DUMONT, 2010, Livro Ata n.1, p.11v).

Com este mesmo teor, os regionalistas de Maringá realizaram, em 1956 e registrado em Ata em 1957, campanhas de arrecadação e doação de alimento como parte das atividades orientadas pela Escola Normal Regional e Escola Normal Secundária. 


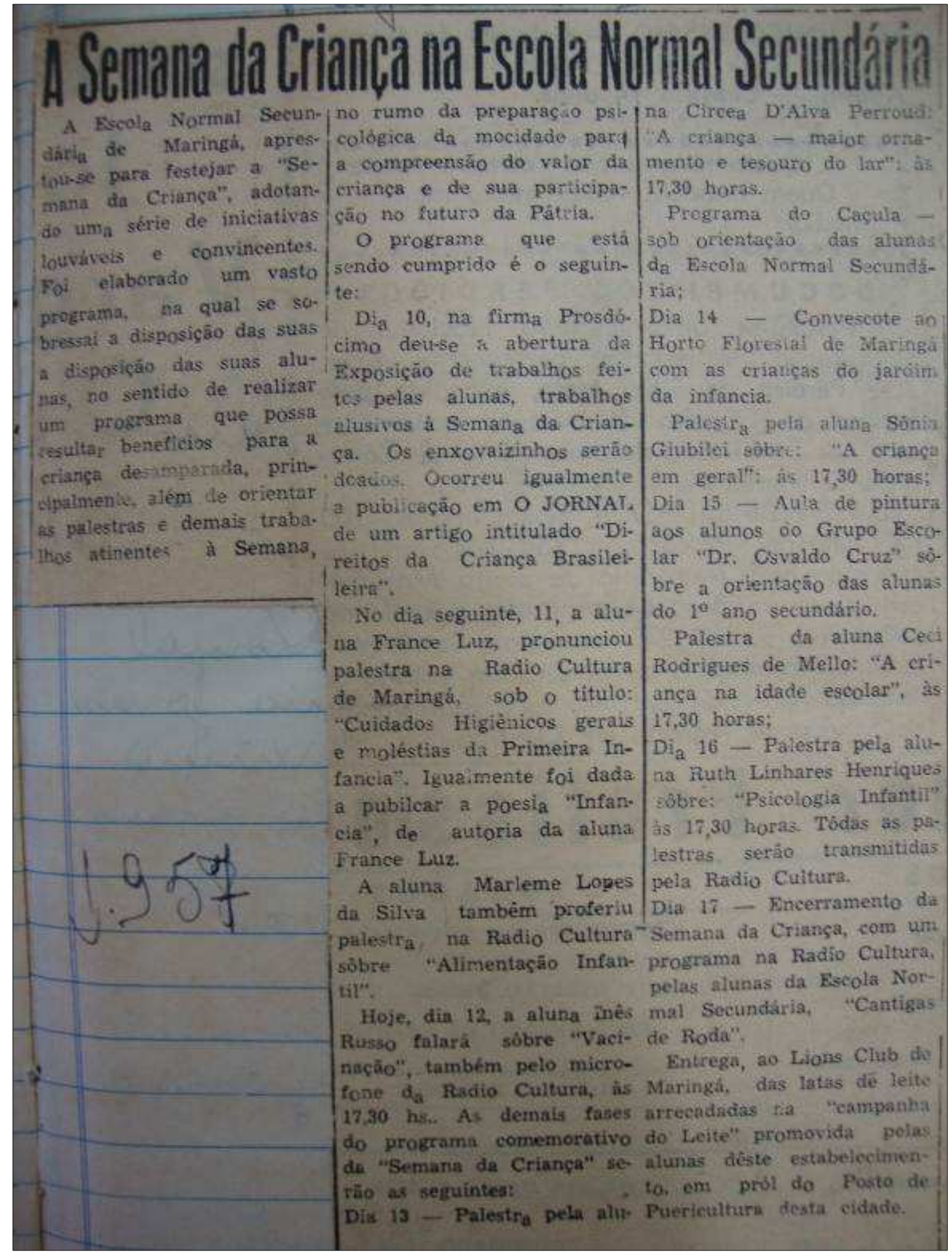

Registro em Ata da Semana da Criança da Escola Normal Regional e Escola Normal Secundária de Maringá. Fonte: INSTITUTO DE EDUCAÇÃO ESTADUAL DE MARINGÁ, 1962.

Sobre estas atividades, transcrevemos abaixo um excerto da declaração de agradecimento do órgão filantrópico à direção da instituição escolar: 
Formulamos a presente a fim de agradecer-lhes a generosa doação de 62 (sessenta e duas) latas de leite em pó à nossa "CAMPANHA DO LEITE P'RO INFÂNCIA", as quais faremos entrega ao Posto de Puericultura de Maringá que fará, por sua vez, a distribuição às crianças pobres e necessitadas. Pela ocasião da nossa próxima entrega de leite ao posto de Puericultura local, teremos a grata satisfação de enviar-lhes convite para assistirem as cerimônias que serão levadas a efeito e esperamos honrarnos com suas presenças. Mais uma vez, pelo gesto verdadeiramente altruístico, confessamos-lhes sinceramente gratos. (INSTITUTO DE EDUCAÇÃO ESTADUAL DE MARINGÁ, 1956, p. 11).

A Secretaria de Educação e Cultura, por meio do Serviço do Ensino Normal, avalizava estas práticas e encaminhava às Escolas Normais Regionais orientações neste sentido. Desta forma, às Escolas Normais, era direcionada esta responsabilidade: a de formar professores preocupados com a preservação da infância, dos cuidados com sua família e com olhar sobre a carência dos mais pobres. Uma proposta de educação assistencialista que objetivava "[...] disciplinar e apaziguar as relações sociais" (KUHLMANN JÚNIOR, 1998, p. 181).

No Programa para as Escolas Normais Regionais desenvolvido por Erasmo Pilotto em 1952, o educador destaca que uma das finalidades do curso era formar o professorregente para que, ao conhecer as dificuldades da população local, este pudesse fazer da escola "[...] um centro de vida social e educativo de tôda a comunidade [...]", com isso o professor atuaria em conjunto com os pais, orientando-os no cumprimento de suas responsabilidades com os filhos. Assim, o programa de ensino das Escolas Normais Regionais deveria estar estreitamente vinculado à formação da personalidade do professor para, ao alargar sua cultura, destinar a sua ação a objetivos assistenciais junto à comunidade, fosse ela rural ou urbana. (PILLOTO, 1952, p. 48).

\section{Práticas pedagógicas de cunho cívico-patriótico}

Os ideais republicanos presentes nas primeiras décadas de século XX no Brasil estavam embasados na ideia de nacionalizar o povo pelo amor à Pátria e o enaltecimento dos símbolos e heróis nacionais. Mais tarde, reforçados pela industrialização que emergia na segunda metade daquele século, consolidava-se um novo nacionalismo pela ideia de uma educação do cidadão pátrio para uma sociedade em processo de urbanização.

No período de abertura das Escolas Normais Regionais em 1946, o Estado do Paraná, sob o governo de Moysés Lupion, regulava a educação paranaense com a marca da educação para o povo e o perfil que se almejava para o professor primário era o de um educador que moldasse o futuro cidadão para a valorização dos valores da família e da pátria. Foi neste período em que a região onde estão localizadas as cidades de Apucarana e Maringá viveu o processo de urbanização de sua população mais intensamente (nas décadas de 1940 até a década de 1960) e a formação educacional para o civismo, foi a tônica da política nacionalista identificada em várias práticas pedagógicas desenvolvidas pelos alunos das Escolas Normais Regionais destas cidades.

Em seu Programa de Ensino Primário, Erasmo Pilotto levava em consideração a formação cívica da criança e a preparação do professor para este caráter educativo. "Auxiliar a formação cívica da criança, fazendo-a sentir a vida de sua Pátria e as suas necessidades [...]." (PILOTTO, 1946, p. 99). Por estar em consonância com a Lei Orgânica do Ensino Normal $\mathrm{n}^{\circ}$ 8.530/46, um de seus pontos para os programas de ensino e orientação metodológica era que: "a educação moral e cívica não deverá constar de 
programas específicos, mas resultará do espírito e da execução de todo o ensino." (BRASIL, 1946b, Art. 14, alínea b).

Como atividade de cunho cívico-patriótico que permeava a formação dos regionalistas destacamos a confecção de cartazes de bustos de grandes vultos pátrios, expostos em momentos cívicos, como desfiles e hasteamento de bandeiras. Nestes desfiles cívicos em datas comemorativas nacionais e locais, a utilização de carros alegóricos, da fanfarra, das bandeiras e dos dísticos ${ }^{5}$, assim como a presença dos normalistas era indispensável, como fica evidenciada nas fotos das normalistas da Escola Normal Regional Pestalozzi, em desfile na cidade de Apucarana no ano de 1949 e das normalistas da Escola Normal Regional Eduardo Claparèd, em desfile na cidade de Maringá, no ano de 1963:

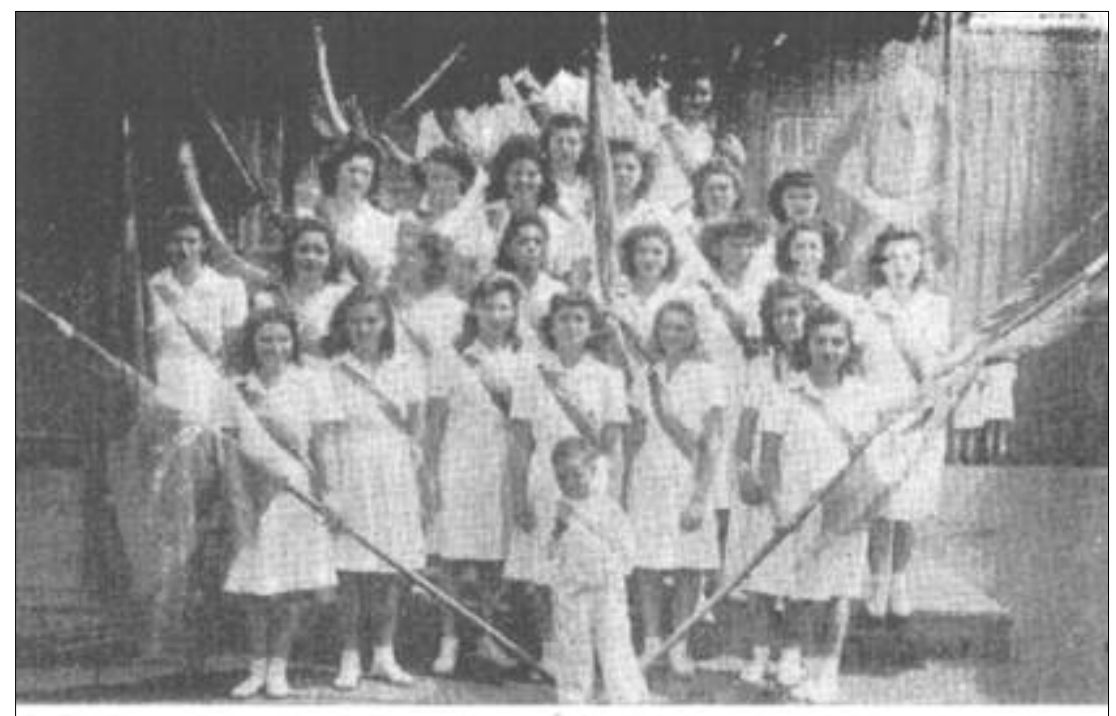

Normalistas da Escola Normal Regional Pestalozzi, em 1949. Fonte: APUCARANA, 1994.

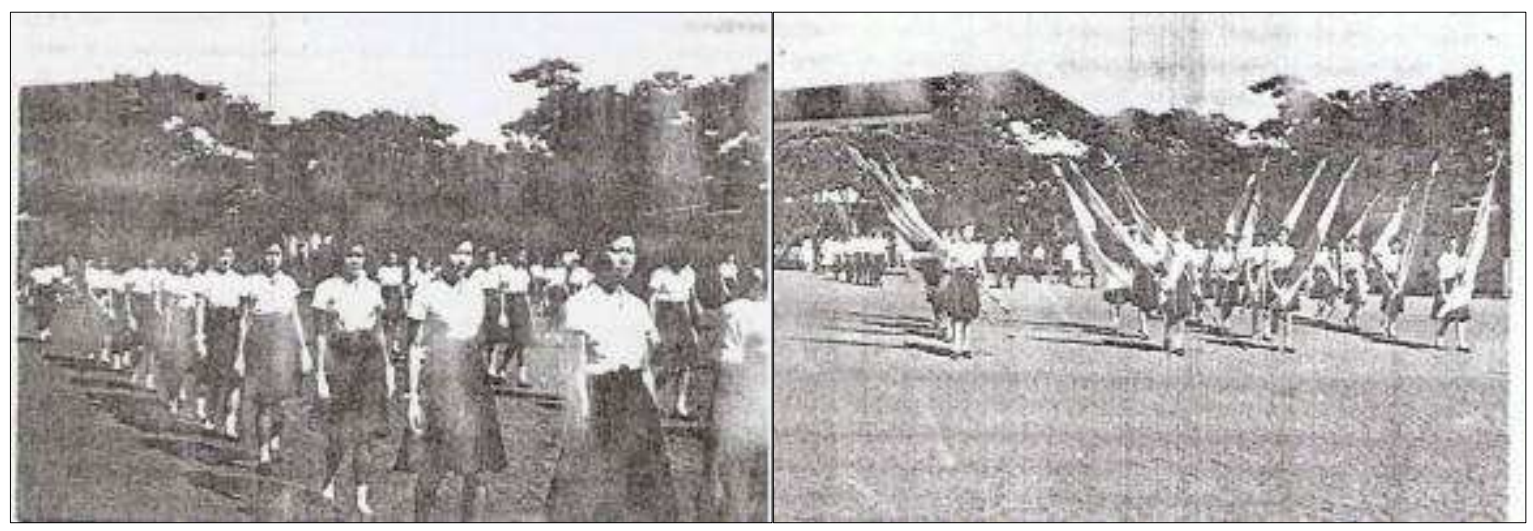

Normalistas da Escola Normal Ginasial (anteriormente Regional) Eduardo Claparèd, em 1963.

Fonte: COLÉGIO ESTADUAL JOÃO XXII, 2010.

Verificamos nos registros das instituições pesquisadas que as comemorações de datas e personalidades nacionais e municipais e o enaltecimento dos vultos pátrios foram incorporados como atividades das disciplinas do curso, especialmente aquelas que se referiam diretamente à atuação no ensino primário. Para a execução destas atividades as escolas recebiam orientações da Secretaria de Educação e Cultura, por meio do Serviço de 
Ensino Normal, como nos mostra o relatório a seguir enviado à chefia do Ensino Normal em 1957, pela direção da Escola Normal Regional Eduardo Claparèd, de Maringá:

Cumprindo determinação dessa Secretaria de Educação, passo a relatar os acontecimentos de primeiro semestre, de acôrdo com a Instrução $\mathrm{n}^{\circ} 19$. [...] $4^{\circ}$ - Resumo das comemorações - Tôdas as datas cívicas foram comemoradas com o devido entusiasmo e patriotismo, quer pelo corpo docente, quer pelo discente. Até 30 de junho dêste ano, foram as seguintes as festividades; Aula Inaugural, Descobrimento do Brasil, Tiradentes, Dia do Trabalho, $10^{\circ}$ Aniversário de Maringá, Abolição da Escravatura (alusão - palestra), se revestindo de modo geral, de grande sentimento cívico [...]. (COLÉGIO ESTADUAL JOÃO XXIII, 2010).

O sentimento cívico, enfatizado pela direção da instituição, constituía em cumprir com patriotismo as normas estabelecidas e em considerar a representatividade que os regionalistas tinham na comunidade local. Esta cultura cívica se apresentava de variadas formas. Verificamos que, até mesmo pelo zelo do uniforme dos regionalistas, revelavam-se estes valores, uma vez que a uniformidade que a roupa da escola propunha representava a disciplina, a ordem e o respeito às regras. Sentimentos de grande valor na sociedade da época e na ideologia nacionalista, presentes na educação.

Outros momentos em que se evidenciava este cunho eram nas solenidades de aulas inaugurais, nos discursos em eventos e no juramento das formaturas. Como no juramento dos formandos de 1962 da Escola Normal Regional Pestalozzi, de Apucarana, registrado na contracapa do convite de formatura:

Prometo respeitar as leis da República e as do Estado do Paraná, observar os regulamentos da Secretaria de Educação e Cultura do Estado, cumprir os deveres do cargo de Professor Regente Primário, com zêlo, dedicação e patriotismo. (HERVATINI, 2010).

Como fica evidenciado, o nacionalismo na educação estava claramente marcado nos discursos e nas atividades práticas das Escolas Normais Regionais pesquisadas, procurando abafar as tensões políticas e sociais que o período de governo ditatorial tinha gerado. Neste contexto o civismo aparece como ponto central nos projetos e discursos educacionais, uma vez que fortalece o controle ideológico da sociedade.

A nacionalização na educação estava claramente marcada nas orientações e nas práticas pedagógicas dos regionalistas das Escolas Normais Regionais pesquisadas, demonstrando como o magistério primário fora conclamado a servir a pátria durante as primeiras décadas da República, durante a "[...] cruzada nacionalista implementada pelo governo de Getúlio Vargas e disseminada no país" ao longo do século XX. (SOUZA, 2008, p. 74).

Como fica evidenciado, o nacionalismo na educação estava claramente marcado nos discursos e nas atividades práticas das Escolas Normais Regionais pesquisadas, procurando abafar as tensões políticas e sociais que o período de governo ditatorial tinha gerado. Neste sentido, o civismo aparece como ponto central nos projetos e discursos educacionais, uma vez que fortalece o controle ideológico da sociedade. Concordamos com Souza (2008, p. 69) quando explica que, na realidade,

[...] as comemorações cívicas, as festas escolares e práticas como o escotismo, o orfeão infantil, o culto ao pavilhão nacional, a entrega do primeiro livro, a distribuição de prêmios e diplomas, entre outras, 
contribuíram para a disseminação de idéas, valores e representações sociais ligadas à construção da nacionalidade - o respeito aos símbolos nacionais, o sentimento de patriotismo, a legitimação do imaginário sociopolítico, o cultivo da memória nacional - e o reconhecimento do valor social e cultural da escola.

A nacionalização na educação estava claramente marcada nas orientações e nas práticas pedagógicas dos regionalistas das Escolas Normais Regionais pesquisadas, demonstrando como o magistério primário fora conclamado a servir a pátria durante as primeiras décadas da República, durante a "[...] cruzada nacionalista implementada pelo governo de Getúlio Vargas e disseminada no país" (SOUZA, 2008, p. 74) ao longo do século XX.

\section{Práticas pedagógicas de cunho religioso}

Segundo Saviani (2008), além de se intencionar uma educação escolar voltada para a alfabetização popular, a mudança que se deu na Escola Normal, com a Reforma Capanema de 1942 e 1946, procurava apaziguar o conflito entre uma formação de caráter laico e científico e os valores morais e religiosos da Igreja Católica. Neste sentido o Paraná apresentou a vertente escolanovista de cunho religioso, presente na formação de professores, tendo como seu expoente Erasmo Pilotto.

Paralelamente às orientações humanistas de Erasmo Pilotto na década de 1940, entrou em vigor, em âmbito nacional, o Ensino Religioso como disciplina da Escola Normal. O ensino religioso foi previsto na Lei Orgânica do Ensino Normal em seu Artigo 15, com a seguinte normativa:

O ensino religioso poderá ser contemplado como disciplina dos cursos de primeiro e segundo ciclos do ensino normal, não podendo constituir, porém, objeto de obrigação de mestres ou professores, nem de frequência compulsória por parte dos alunos. (BRASIL, 1946b).

A condição de poder ser contemplado como disciplina fez com que as Escolas Normais Regionais, assim como as Secundárias, ofertassem o ensino religioso que deveria, de acordo com a legislação, ser ofertado de acordo com a confissão religiosa do aluno. Porém a realidade nos mostrou que foi um ensino religioso fundamentado em dogmas católicos. A sua frequência era facultativa. No entanto, mesmo dependendo do desejo pessoal do regionalista em assistir, ou não, às aulas de em sino religioso nas Escolas Normais Regionais, a disciplina de Religião era ofertada dentro do horário escolar, apesar de não constar na matriz curricular de disciplinas.

As atividades de cunho religioso realizadas pela Escola Normal Regional se apresentavam em momentos de oratória, na confecção de lembrancinhas de festividades do calendário católico, em confraternizações e momentos de orações. Todas estas atividades eram realizadas e orientadas por seus professores. Vejamos o relato de uma destas situações:

No dia da Páscoa [de 1959] os alunos da Escola Normal [Regional] ofereceram uma linda festinha aos alunos do Jardim de Infância e PréPrimário do Grupo Escolar Alberto Santos Dumont. Entregaram, às crianças, os ninhos que haviam confeccionado nas aulas de Desenho e Trabalhos Manuais. (COLÉGIO ESTADUAL ALBERTO SANTOS DUMONT, 2010, Livro Ata n. 1, p. 6). 
Não somente datas religiosas do calendário católico eram lembradas, era bastante comum, nas atividades escolares, a presença de representantes da Igreja como sacerdotes e bispos. Nestas ocasiões, eram celebradas missas, realizados bênçãos e momentos de orações, como, por exemplo, o Dia das Mães. Em formaturas, era de praxe a missa de ação de graças e bênçãos dos anéis dos formandos.

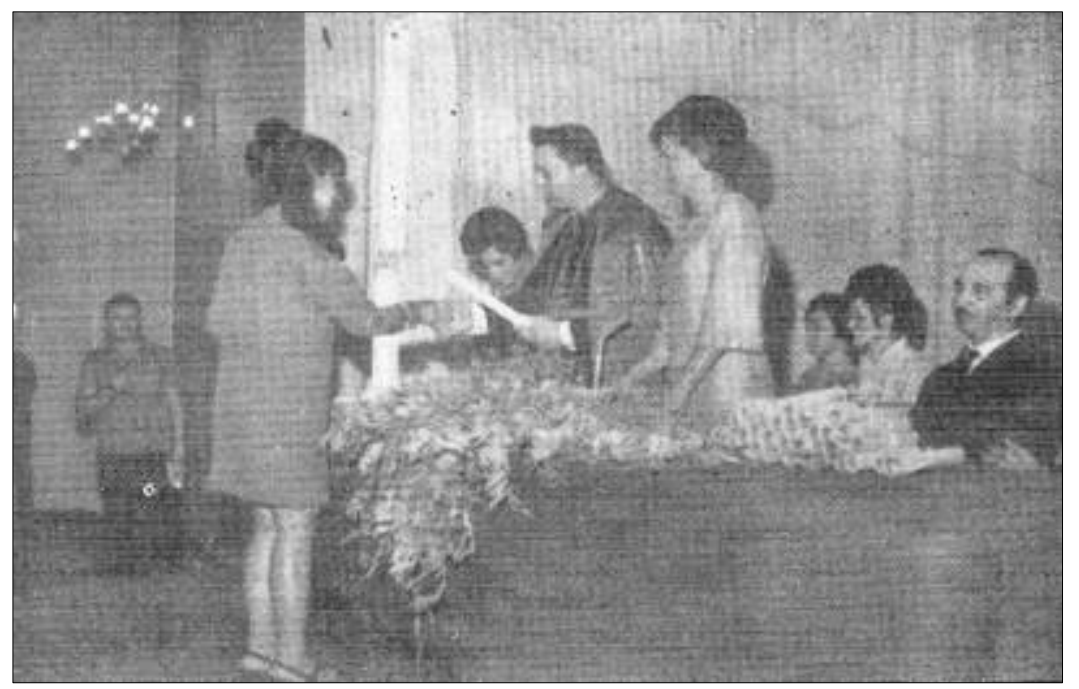

Presença do Bispo de Apucarana, Dom Romeu Alberti na formatura da Escola Normal Ginasial Pestalozzi, Apucarana, 1967.

Fonte: Apucarana (1967).

A presença dos padres e bispos nos eventos escolares impunha um ar solene à ocasião. Quanto mais importante fosse uma solenidade, maior era o grau hierárquico dos representantes da Igreja Católica presentes, como observamos na foto anterior em que o bispo de Apucarana faz a entrega do certificado a uma formanda. Esta situação pode ser considerada que, não somente de forma simbólica, quem estava, naquele momento, outorgando o cargo de professora à normalista era a própria Igreja. A simbologia educacional (anel e diploma de formatura) se relacionava diretamente com a simbologia religiosa (benção e entrega por um religioso), constituindo, naquele espaço, a cultura escolar ideal para a formação do professor (FARIA FILHO, 2004).

A presença da Igreja nas Escolas Normais Regionais de Apucarana e de Maringá exerceu, no período histórico específico, o papel predominante para a organização e a manutenção da ordem sociomoral, por sua característica hierarquizante, pela pregação da igualdade e da não geração de conflito entre as classes sociais (SOUZA, 2006).

Esta influência católica na formação de professores primários, especialmente do interior do Estado e na zona rural, era interessante para o Estado Novo que, sem romper com as estruturas tradicionais, procurava modernizar a educação.

\section{Práticas pedagógicas relacionadas à docência no ensino primário}

Na formação de professores para ensino primário do interior do Paraná, de acordo com a legislação (BRASIL, 1946b) e com o Programa de Pilotto (1946), os regionalistas deveriam estar presentes nas situações de ensino em sala de aula com competência. Para tal, fazia-se necessária a adequada formação dos regionalistas, tanto de caráter teórica quanto prática, para atuarem nessas escolas primárias. A prática de ensino seria feita em 
"[...] exercícios de observação e de participação real no trabalho docente, de tal modo que nela se integrem os conhecimentos teóricos e técnicos de todo o curso." (BRASIL, 1946b, Art. 14, alínea d).

Conforme a Lei Orgânica do Ensino Normal, os alunos das Escolas Normais Regionais deveriam realizar suas atividades práticas nas escolas isoladas, porém constatamos nos registros históricos das escolas os relatos de realização destas atividades também nos grupos escolares locais. As práticas pedagógicas de docência consistiam em prestar assistência às aulas dadas pelos professores ou pelos próprios colegas, em assumir a regência das aulas sob a observação e a avaliação dos professores regentes da classe e da direção da Escola Normal. (PILOTTO, 1952).

Quanto ao exercício de observação e registro das aulas dadas pelas professoras das escolas isoladas, ou pelos próprios colegas normalistas, encontramos a narrativa a seguir:

No dia 25 de maio [de 1957] os alunos da $4^{\mathrm{a}}$ série fizeram visita a outra escola isolada, onde fomos recebidos com um discurso pronunciado por uma aluna. Um dos alunos do Curso Normal Regional deu aula de Português para as crianças e depois foram organizadas diversas brincadeiras no pátio. As observações necessárias e a crítica da aula foram anotadas nos cadernos individuais dos alunos. (COLÉGIO ESTADUAL ALBERTO SANTOS DUMONT, 2010, Livro Ata n. 1, p. $2 \mathrm{v}$.$) .$

A observação do meio natural e social, o chamado estudo do meio era realizado, especialmente no meio rural, nas escolas isoladas, como parte integrante do processo de formação. Encontramos uma situação bastante interessante realizada por alunos da Escola Normal Regional Pestalozzi, de Apucarana, em 1958, em uma fazenda do município.

Queremos destacar que, desde 1890, quando a reforma da Escola Normal paulista e a criação dos grupos escolares disseminaram a adoção do método de ensino intuitivo na formação de professores, o uso dos espaços de aprendizagem foi reorganizado. O método primava pela educação dos sentidos, ou seja, a aprendizagem se daria por meio da apreensão sensorial dos alunos e, segundo Rui Barbosa, não deveria se configurar como uma disciplina ou parte do programa de ensino, mas constituir-se como método de estudo (SCHELBAUER, 2005).

Instituída com base neste método, a prática de passeios escolares, para o conhecimento do meio que cercava o aluno, foi intensamente valorizada para promover a aprendizagem, e por ser considerado um método que tinha por princípio respeitar o interesse do aluno e sua participação ativa no processo de aprendizagem, foi incorporado ao movimento escolanovista e às propostas de Erasmo Pilotto.

Para a formação específica em atividades propriamente de docência, ou seja, de ministrarem aulas no ensino primário, verificamos que houve atividades práticas de regências, explicação de matérias isoladas, atividades de literatura infantil e recreativas, realizadas pelos regionalistas. Em todas elas, contou-se com a presença de colegas e professores do Curso Normal, como verificamos nas atas das escolas pesquisadas.

Com referência às orientações locais recebidas para a realização das regências no ensino primário, registramos a visita da direção da Escola Normal Regional Pestalozzi de Apucarana, em 9 de setembro de 1960, à Inspetoria Regional do Ensino Normal. Nesta data, a direção da instituição escolar trouxe a seguinte normativa: "A regência de classe para os alunos da $4^{a}$ série deve ser feita com duração mínima de três dias. O seu planejamento, bem como o julgamento será baseado no modêlo que recebemos na 
ocasião". (COLÉGIO ESTADUAL ALBERTO SANTOS DUMONT, 2010, Livro Ata n. 1, p. 14v.).

Como foi possível verificarmos em fichas de regência coletadas, a apresentação da matéria deveria ser precedida pela motivação, com a descrição de como foi despertado o interesse dos alunos. Quanto ao desenvolvimento da aula, além do conteúdo, o registro da forma como foi aplicado, fixado e verificado, além de ser registrado se houve aulas ocasionais e globalizadas. Para o desenvolvimento do conteúdo, a utilização do material didático e o uso adequado do quadro negro era outro critério de avaliação. Não somente as regências determinavam a utilização de materiais didáticos, como as aulas de alguma matéria determinada, era o caso das aulas de histórias infantis, como parte da disciplina de Didática e Prática de Ensino.

As práticas de leitura no ensino primário foram bastante valorizadas por Pilotto (1946), no sentido de desenvolver tanto nas crianças quanto nos normalistas um bom aperfeiçoamento da leitura, para serem excelentes leitores e grandes narradores. Nas práticas pedagógicas de docência realizadas nas escolas isoladas, foram bastante exploradas as chamadas fichas de leitura. Estas fichas eram confeccionadas pelos regionalistas para utilização na alfabetização e no treino de leitura de pequenos textos para os alunos do ensino primário.

Recuperarmos e analisarmos as práticas pedagógicas das Escolas Normais Regionais das duas cidades pesquisadas nos abriu a possibilidade de compreender como estas se efetivaram em suas localidades. Verificamos as nuances que a nacionalização do país apresentou nas Escolas Normais Regionais de Apucarana e Maringá, demonstrada pelas ações de manutenção das escolas primárias, seja predial ou de material pedagógico, o exercício do assistencialismo na comunidade local, o culto à pátria pelo civismo escolar, a presença da religiosidade católica no ensino primário e na formação do professor e a forma como as atividades de docência se realizaram no contexto das orientações pedagógicas e legais.

A formação de professores pelas Escolas Normais Regionais se destinava a formar professores para a zona rural, a fim de que proporcionasse melhoria das formas de vida da população, conforme almejava Erasmo Pilotto em sua Escola Serena. (PILOTTO, 1946). Preocupação esta que iria sobrepor-se ao treinamento e à aplicação de técnicas educativas, muitas vezes impossíveis de serem realizadas satisfatoriamente devido às precárias condições materiais das escolas e dos alunos. Mesmo com a oferta de disciplinas que atendiam às características locais para uma formação de professores para as escolas primárias do interior, as práticas pedagógicas se limitavam, quando muito, em aplicação de exercícios docentes planejados para alunos e escolas primárias consideradas ideais.

As ideias de Erasmo Pilotto para a educação primária no Paraná foram readequadas às realidades de precariedade econômica da grande maioria dos alunos em idade escolar no interior do Estado. Para a formação de professores regentes de ensino primário, a adequação de seu programa enfatizou, sobremaneira, a alfabetização, tendo como principal preocupação o domínio básico do ensinar a ler, escrever e contar, de modo a garantir sua tese de que a "Educação é Direito de Todos" (1952).

Desta forma, a formação de professores para a educação primária no interior propiciou o exercício de práticas pedagógicas com a aplicação de conteúdos escolares minimizados, tendo como justificativa a carência socioeconômica dos alunos do ensino primário e a precariedade das escolas do interior.

Consideramos, pois, que foi secundária a observação das atividades de ensino e aprendizagem da escola primária, por ser considerada de maior relevância para os regionalistas a observação das necessidades físicas das escolas isoladas e das 
peculiaridades da zona rural, como forma de conhecimento prático da realidade das escolas do ensino primário e do cenário rural do norte do Estado, responsável pelo desenvolvimento dos seus centros urbanos.

Ficava inferiorizada a formação pedagógica mais consistente, no sentido de reflexão sobre a prática durante o processo de ensino e aprendizagem na formação de professores regentes para o ensino primário. Constatação esta, responsável pelos futuros estudos e orientações didáticas que Erasmo Pilotto desenvolveria para o processo de alfabetização no ensino primário no Paraná e que alcançaria repercussão nacional.

\section{Referências}

APUCARANA. Prefeitura Municipal. Vivo Apucarana. Publicação Comemorativa ao Cinquentenário de Apucarana. 1994.

APUCARANA. Escola Normal Ginasial Pestalozzi revive na sua formatura a vida da escola. Revista Destaque, ed. Anual, p. 31-32, 1967.

APUCARANA. Fundação Cultural. Museu Etnográfico Municipal. Arquivo histórico. 2011.

BALHANA, Altiva Pilatti; MACHADO, Brasil Pinheiro; WESTPHALEN. História do Paraná. v. 1. Curitiba: Grafipar, 1969.

BRASIL. Lei Orgânica do Ensino Normal. Decreto-lei $n^{\circ} 8.530$, de 02 de janeiro de 1946b. Disponível em: <http://www.soleis.adv.br/leiorganicaensinonormal.htm>. Acesso em: 25 nov. 2009.

COLÉGIO ESTADUAL ALBERTO SANTOS DUMONT. Livro Ata n⿳ 1: Histórico do Curso Normal Regional de Apucarana. p. 1-23, Apucarana, PR, 2010.

COLÉGIO ESTADUAL JOÃO XXIII. Acervo histórico. Maringá, PR, 2010.

FARIA FILHO, Luciano Mendes de et al. A cultura escolar como categoria de análise e como campo de investigação na história da educação brasileira. Revista Educação e Pesquisa, São Paulo, v. 30, n. 1, p. 139-159, jan./abr. 2004. Disponível em: < http://www.scielo.br/pdf/ep/v30n1/a08v30n1.pdf >. Acesso em: 25 mar. 2011.

HERVATINI. José Carlos. Acervo pessoal. Borrazópolis, PR, 2010.

HERVATINI, Luciana. A Escola Normal Regional e suas Práticas Pedagógicas: dois retratos de um mesmo cenário no interior do Paraná. $256 \mathrm{fls}$. Dissertação (Mestrado em Educação) - Universidade Estadual de Maringá. Orientadora: Prof ${ }^{\mathrm{a}}$. Dr ${ }^{\mathrm{a}}$. Analete Regina Schelbauer. Maringá, PR, 2011.

INSTITUTO DE EDUCAÇÃO ESTADUAL DE MARINGÁ. Livro Ata do histórico da Escola Normal Secundária de Maringá. Maringá, PR, 1962.

INSTITUTO DE EDUCAÇÃO ESTADUAL DE MARINGÁ. Projeto Político Pedagógico. 2006. Disponível em: < http://ieem.com.br/arquivos/ppp.pdf>. Acesso em: 27 
jul. 2010.

KUHLMANN JÚNIOR, Moysés. Infância e educação infantil: uma abordagem histórica. Porto Alegre: Mediação, 1998.

MIGUEL, Maria Elisabeth Blanck. A formação do professor e a organização social do trabalho. Curitiba: Ed. da UFPR, 1997.

PILOTTO, Erasmo. Prática da escola serena. Curitiba: João Haupt, 1946.

PILOTTO, Erasmo. A educação é direito de todos. Curitiba: Max Roesner, 1952.

SAVIANI, Dermeval.A pedagogia no Brasil: História e teoria. Campinas, SP: Autores Associados, 2008a. (Coleção memória da educação).

SCHELBAUER, Analete Regina. O método intuitivo e lições de coisas no Brasil do século XIX. In: STEPHANOU, Maria; BASTOS, Maria Helena Camara (Orgs.). Histórias e memórias da educação no Brasil. Vol. II: século XIX, 2. ed. Petrópolis, RJ: Vozes, 2005. p. 132 - 149.

SOUZA, Rita de Cássia de. Não premiarás, não castigarás, não ralharás: dispositivos disciplinas em Grupos Escolares de Belo Horizonte (1925-1955). 2006. Tese (Doutorado em Educação) - Universidade de São Paulo, Faculdade de Educação, São Paulo, 2006.

SOUZA, Rosa Fátima de. História da organização do trabalho escolar e do currículo do século XX: (ensino primário e secundário no Brasil). v. 2, São Paulo: Cortez, 2008.

Notas:

\footnotetext{
${ }^{1}$ Professora de Didática e Prática de Ensino e Pedagoga da Rede Estadual de Educação do Estado do Paraná. E-mail: lu.hervatini@hotmail.com.br; luhervatini@seed.pr.gov.br

${ }^{2}$ Professora do Departamento de Teoria e Prática da Educação e do Programa de Pós-Graduação em Educação da Universidade Estadual de Maringá. E-mail: $\underline{\text { arschelbauer@uem.br }}$

${ }^{3}$ Sobre a formação de professores nas Escolas Normais Regionais de Apucarana e Maringá, ver Hervatini (2011).

${ }^{4}$ Denominação da área compreendida entre os rios Ivaí e Piquiri, durante sua colonização de 1940 a 1960 (BALHANA; MACHADO; WESPHALEN, 1969).

${ }^{5}$ Utilizado como símbolo cívico em atividades escolares e esportivas ao representar uma escola, um time ou um grupo. Significado: s.m. Frase, sentença ou conceito expresso em dois versos. Letreiro, rótulo, divisa. Disponível em: <http://www.dicio.com.br/distico/> Acesso em: 26 jul. 2010.
}

Recebido em: $\quad 05 / 12 / 11$

Aprovado em: $\quad$ 10/02/12 